\title{
Statyba
}

\section{ADAPTIVE FINITE ELEMENT STRATEGY FOR FREE VIBRATION PROBLEMS}

\section{R. Baušys}

To cite this article: R. Baušys (1997) ADAPTIVE FINITE ELEMENT STRATEGY FOR FREE VIBRATION PROBLEMS, Statyba, 3:9, 26-33, DOI: 10.1080/13921525.1997.10531668

To link to this article: https://doi.org/10.1080/13921525.1997.10531668

曲 Published online: 26 Jul 2012.

Submit your article to this journal

Џ Article views: 51 


\section{ADAPTIVE FINITE ELEMENT STRATEGY FOR FREE VIBRATION PROBLEMS}

\section{R. Baušys}

\section{Introduction}

The advent of modern computer technology and the finite element technique provided a very powerful tool for solving complex problems in engineering practice. One of the main concerns in a finite element analysis is the adequacy of the finite element mesh. Since the quality of the finite element approximated solutions directly depends on the quality of meshes, an additional process to improve the quality of meshes is necessary for reliable finite element approximations. Late in the 70's, adaptive methods have become more and more important in finite elements methods. Since the pioneering works [1] [2] there has been a great development in adaptive methods. The aim of all adaptive methods is to minimize computational cost for calculation of a discrete solution where the error between exact solution and the discrete solution is within a prescribed tolerance.

Any adaptive finite element strategy has two major components:

1) Error estimation. This includes the methods and algorithms used for the estimation of the error of the approximate solutions. The most important ingredient of the error estimation is the construction of the new solution of a higher quality since the exact solution for complex engineering problems is generally unknown. Typically, this new improved solution is obtained by a posteriori procedure which utilise finite element solution itself.

2) Mesh optimization. This refers to the techniques which are used to predict the optimal distribution of the parameters of the approximation based on the estimated error and the procedures which are employed in the adaptation of the approximation.

Adaptive strategies can be carried out in various ways, and to date well-known approaches for reducing the discretization error can be classified into four main categories as follows:

1) $h$-version, in which the density of finite elements is increased or decreased using the same interpolation order. This approach is characterized by irregular meshes with non-uniformly sized elements. This technique is the most popular adaptive strategy [3].

2) p-version, which fixes the finite element mesh and increases interpolation order of local approximation in each element or patch of elements. The polynomial order is increased progressively, if the error of discretization is larger than a prescribed tolerance. It is known that $p$-version provides a higher rate of convergence than $h$-version, but the computational implementation of this approach is more complicated [4].

3) $h$-p-version, a proper combination of the $h$ version and $p$-version. This technique provides a very high rate of convergence [5].

4) r-version, which locally clusters or coarsens the nodes of a grid with fixed topology by relocating them in order to satisfy a set of optimality conditions. The use of this version is quite limited because it is quite difficult to achieve a significant improvement.

The aim of the adaptive strategies is to seek a finite element solution which not only satisfies a prespecified level of accuracy but is also associated with a reasonably optimal mesh. The optimal finite element mesh has the property that distribution of the error should be equal between each existing element. There exist several criteria about definition of the optimal mesh. One is the equal distribution of 
global error between all elements, which was first proposed by Zienkiewicz and Zhu [3]. The second criteria is based on the fact that the specific error or the error density is uniformly distributed over a whole domain [6], [7].

We focus our attention on the construction of the $h$-adaptive finite element strategy for free vibration problems. In this paper the ZienkiewiczZhu optimal mesh criterion is employed in the formulation of the adaptivity problem.

\section{Model problem}

Consider elliptic eigenvalue problems of order $2 m$ which are governed by the following differential equation

$$
\lambda \rho u(x)+\widetilde{\nabla}^{T} D \widetilde{\nabla} u(x)=0, \text { in } \Omega
$$

with boundary conditions

$$
\begin{array}{ll}
u(x)=u_{b} & \text { on } \Gamma_{u} \\
\widetilde{\nabla}_{n}^{T} D \widetilde{\nabla} u(x)=0 & \text { on } \Gamma_{\sigma}
\end{array}
$$

where $\widetilde{\nabla}$ is the differential operator, $\widetilde{\nabla}_{n}$ is the boundary operator, $D$ is the constitutive matrix and $\rho$ is the mass density. The $\Omega$ is a spatial domain with the boundary $\Gamma=\Gamma_{u} \bigcup \Gamma_{\sigma}\left(\Gamma_{u} \bigcap \Gamma_{\sigma}=\varnothing\right)$, where $\Gamma_{u}$ is the boundary with essential boundary conditions and $\Gamma_{\sigma}$ is the boundary with natural boundary conditions.

The solutions of Eq. (1) are the functions which give the Rayleigh quotient

$$
R(v)=\frac{a(v, v)}{b(v, v)}
$$

a stationary value when taken over all possible functions $v \in V(\Omega)$ where $v(\Omega) \subset \mathscr{H}^{1}(\Omega)$. Members in $v(\Omega)$ satisfy the essential boundary conditions on the boundary $\Gamma_{u}$. Here $b(v, v)$ is a kinematic energy scalar product on $\Omega$ as

$$
b(v, v)=\int_{\Omega} \rho v^{2} d x
$$

and $a(v, v)$ is a strain energy scalar product on $\Omega$ as

$$
a(v, v)=\int_{\Omega}(\widetilde{\nabla} v)^{T} D \widetilde{\nabla} v d x
$$

The stationary values of $R(v)$ are eigenvalues $\lambda_{i}$ and the corresponding functions $u_{i}$ are the eigenfunctions. When a finite element discretization is applied, the stationary values of the Rayleigh quotient are determined over a finite dimensional subspace $v(\Omega)^{h}$ of the space of admissible functions $\vartheta(\Omega)$. In association with a spatial finite element mesh space $\eta_{h}$ we define a finite dimensional space $v(\Omega)_{p}^{h} \subset v(\Omega)$ in which members are piecewise continuous functions over each space element $\tau$ as

$$
\mathcal{V}(\Omega)_{p}^{h}=\left\{v^{h} \in \mathbb{F}^{l}(\Omega)\left|v^{h}\right|_{\tau} \in \mathcal{P}_{p} \quad \forall \tau \in \mathcal{I}_{h}\right\}
$$

where $\mathcal{P}_{p}$ is the set of $p$-th order polynomials. A function $v^{h}$ is expanded in the form $v^{h}=\sum_{j=1}^{n} N_{j}(x, y) u_{j}$, where $N_{j}(x, y)$ are local basis functions and $u_{j}$ are generalized displacements to be determined.

On substituting this expression for $v^{h}$ into Rayleigh quotient expression, we obtain

$$
R\left(v^{h}\right)=\frac{\left(u^{h}\right)^{T} K u^{h}}{\left(u^{h}\right)^{T} M u^{h}}
$$

where $K$ is the stiffness matrix and $M$ is the consistent mass matrix of the structure.

The stationary values of the $R\left(v^{h}\right)$ are found by solving the generalized eigenvalue problem

$$
\left(\boldsymbol{K} \cdot \lambda^{h} \boldsymbol{M}\right) \boldsymbol{u}^{h}=0, \lambda^{h}=\left(\omega^{h}\right)^{2} .
$$

Equation (9) is of the form of a linear generalized eigenvalue problem for the finite dimensional discrete problem, with eigenvalues $\lambda_{i}^{h}$ being equal to the squares of the eigenfrequencies $\omega_{i}^{h}$ of the appropriate mode and $u_{i}^{h}$ is a displacement field representing the corresponding eigenvector of the vibration mode.

\section{Error estimation}

Estimation of the errors can either be performed before FE-calculation, so-called a priori error estimation, or after FE-solution a posteriori error estimation. Traditional error estimates for 
the asymptotic rate of convergence as the mesh size tends to zero. For the elliptic eigenvalue problem of order $2 m, a$ priori error estimation of the eigenfrequencies for standard Galerkin finite element approximation is given as [8]

$$
\Delta \omega_{i}^{h} \leq C_{1} h^{2(p+1-m)} \omega_{i}^{(p+1) / m}
$$

where $\Delta \omega_{i}^{h}=\omega_{i}^{h}-\omega_{i}$ and the $L_{2}$ estimate for the eigenmodes is

$$
\left\|\boldsymbol{u}_{i}^{h}-\boldsymbol{u}_{i}\right\|_{0} \leq C_{2} h^{\sigma} \omega_{i}^{(p+1) / m}
$$

where $\sigma=\min (p+1,2(p+1-m)), C_{1}$ and $C_{2}$ are positive constants independent of $h$ and $\omega_{i}, h$ is the maximum element size, $p$ is the degree of complete polynomial appearing in the element basis functions and $2 m$ is the order of the differential operator $\widetilde{\nabla}$. Unfortunately, this gives us a little direct information about true error distribution for a fixed grid size.

In the posteriori error estimation we get an estimation $\Delta \bar{\omega}_{i}$ of the error $\Delta \omega_{i}$ in the form

$$
\Delta \omega_{i} \cong \Delta \bar{\omega}_{i}=\omega_{i}^{h}-\omega_{i}^{*}
$$

where $\omega_{i}^{*}$ is an approximation of the exact value $\omega_{i}$ of higher accuracy obtained by updating technique in comparison with the finite element solution $\omega_{i}^{h}$. It is clear that the construction the eigensolutions of higher quality plays the most important role for effectivity of this error estimate. The accuracy of these estimates depends on the asymptotic properties of the postprocessed solution. In order to obtain asymptotically exact error estimates, the postprocessed solution should exhibit superior accuracy and rate of convergence that can be expressed as follows

$$
\Delta \omega_{i}^{*} \leq C_{1} h^{2(p+1-m+\alpha)} \omega_{i}^{(p+1) / m}, \quad \alpha \geq 0 .
$$

A new improved finite element solution can be constructed by the local and global updating techniques. Within a framework of the local updating the Superconvergent Patch Recovery technique for displacements (SPRD) is applied to free vibration problems for improving eigenmodes and eigenfrequencies. This approach is based on the fact that the nodal points of the finite element approximation are found to be exceptional points at which the prime variables (displacements) have higher order accuracy with respect to the global accuracy. These points are called the superconvergent points of the finite element solution. The SPRD technique is essentially a least square fit of the prime variables (displacements) at superconvergent points. This approach provides superconvergent displacement field $u_{i}^{*}$ over local element patches. Since the SPRD technique recovers superconvergent displacement field that is at least one order higher than finite element solution, the method can successfully be implemented in error estimation of the finite element solution. From the higher order accuracy displacement field an improved kinetic energy and a strain energy can be calculated and thus an improved eigenfrequency can be obtained using Rayleigh quotient. A separate patch recovery must be made for each eigenmode of interest. This approach is a local updating method, so no global system of equations has to be constructed and solved. Details are available in [9], [10]. This method does not show sufficient improvement for the higher eigenfrequencies to provide a reliable error estimation. We need improvement of the higher eigenfrequencies, for it is impossible to obtain good results based on the information obtained by performing analysis using a very coarse preliminary mesh.

In order to improve the higher frequencies, we are interested in improving the eigenfrequencies from an initial mesh using base functions of order $p$ to obtain the solution of base functions of order $p+1$. The scheme of deflation accelerated conjugate gradients, 
DACG, can be employed to optimise successive deflated Rayleigh quotients based on a preconditioned conjugate gradient technique is developed as global updating. This technique has been developed in [11]. The idea of global updating is to improve the FE solution of order $p$ by the SPRD method and then use it as the starting trial eigenvector in the preconditioned conjugate gradient scheme to obtain a solution similar to the FE solution of order $p+1$. The SPRD improved solution used as initial trial eigenvector for the modified conjugate gradient scheme put us on the asymptotic phase of the convergence profile. In order to accelerate the speed of convergence of the global updating we use a preconditioning matrix that is a diagonal of the sum of the stiffness and mass matrices. This allow us to keep the computations on an element level which gives a high computational efficiency. We do not seek to determine a fully converged eigenpairs so we restrict the number of the iterations to in advance prescribed quantity. It is also worth noticing that this technique only needs a global matrix equation size of order $p$ and not order $p+1$ of finite element formulation. When we have obtained the global updated solution of order $p+1$ we apply again the SPRD technique to get an improved solution of order $p+2$, thus we have a global-local approach. The details of this global/local updating technique are available in [12], [13].

The absolute errors in eigenfrequencies defined by equation (9) are not convenient for use in practical numerical procedures. This error can be measured in more favoured terms of the relative error in eigenfrequencies which can be expressed as

$$
\bar{\eta}_{i}^{\omega}=\frac{\omega_{i}^{h}-\omega_{i}^{*}}{\omega_{i}^{*}} .
$$

This error measure is only employed as a stopping criterion of the adaptive algorithm. The mesh refinement strategy is based upon an error estimator which indicates the local error distribution. It is a well-known fact that the strain energy has two order lower rate of convergence than the kinetic energy in Rayleigh quotient. It seems to be sufficient to study distribution in strain energy as a basis for a new mesh in the adaptive procedure for free vibration problems. So the measure of the discretization error can be expressed in the same way as for the problems of linear elasticity

$$
\bar{\eta}_{i}^{u}=\frac{\left\|\bar{e}_{i}\right\|}{\left\|u_{i}\right\|} * 100 \%
$$

with

$$
\left\|u_{i}\right\|=\left(\left\|u_{i}^{h}\right\|+\left\|\bar{e}_{i}\right\|\right)^{1 / 2}
$$

where $\|v\|=a(v, v)^{1 / 2}$ and $\bar{e}_{i}=u_{i}^{*}-u_{i}^{h}$. The discretization error term in eigenmodes is calculated on the element level and summed

$$
\|\bar{e}\|^{2}=\sum_{i=1}^{n e l e m}\|\bar{e}\|_{i}^{2}
$$

where nelem is the number of elements in the current mesh.

\section{Adaptive mesh refinement strategy}

The main goal of any adaptive strategy is to construct an optimal finite element mesh. The optimal finite element mesh has the property that distribution of the error energy norm should be equal between each existing element. Adaptive strategies construct sequences of finite element meshes to achieve equidistribution of the error. An error indicator, which provides information about contribution of each element to the global error, must be defined at an element level. We wish to construct an optimal mesh which employs a minimal number of finite elements. The problem in adaptivity for finite element methods may be formulated as follows: 
construct a finite element mesh $T_{h}^{\text {adapt }}=\left\{\Omega_{e} \mid e=1,2, \ldots\right.$, nelem $\}$ with (nearly) as few degrees of freedom, as possible, such as that

$$
\begin{aligned}
& \eta_{i}^{\omega} \leq \eta_{\text {TOL }}^{\omega}, \\
& \eta_{i}^{u} \leq \eta_{\text {TOL }}^{u} .
\end{aligned}
$$

This is a non-linear minimization problem which may be solved approximately in an iterative process. A very important feature of $\eta_{i}^{u}$ is that this quantity contains information on the structure of the error as a function of a mesh parameter $h=h(x)$ which enables us to solve this minimization problem. In free vibration analysis an $h$-adaptive scheme, given in [14], is employed; the adaptive finite element strategy may be constructed as follows:

1. Choose an initial finite element mesh of the domain $T_{h}^{0}$; let $T_{h}=T_{h}^{0}$.

2. For given the mesh $T_{h}$, compute finite element solution of free vibration problem $\omega_{i}^{h}, \boldsymbol{u}_{i}^{h}$.

3. Determine the resulting error in eigenfrequencies $\bar{\eta}_{i}^{\omega}$ (equation (14)) and error distribution in eigenmodes $\left\|\vec{e}_{i}\right\|_{j}$ (equation (17)) and check for convergence (equation (19)).

4. If the error tolerance in eigenfrequencies is met, then stop; otherwise a new mesh is generated.

5. Compute the permissible error $\left\|\bar{e}_{i}\right\|_{j, \text { new }}$ for the optimal mesh, using the principle of equidistribution of error, namely

$$
\|\bar{e}\|_{i, n e w}=\frac{\eta_{T O L}^{\mathrm{u}}}{100}\left(\frac{\left\|u^{h}\right\|^{2}+\|\bar{e}\|^{2}}{\text { nelem }}\right)^{1 / 2}
$$

Here nelem is the number of elements on the current mesh $T_{h}$.

6. For each element $\Omega_{e}$, predict the new element mesh size from the formula

$$
h_{\text {new }}=\frac{1}{\xi^{1 / r}} h_{\text {old }}, \xi=\frac{\left\|\bar{e}_{i}\right\|_{j}}{\left\|\bar{e}_{i}\right\|_{j, \text { new }}}
$$

where $r$ is the exponent which depends on the degree of the complete polynomial appearing in the element basis functions and the regularity of the solution (see [14]).
7. Use $h$-remeshing scheme to construct a new grid $T_{h}^{\text {new }}$ which satisfies constraints (18) and (19). Let $T_{h}=T_{h}^{\text {new }}$ and go to 2 .

Note that if we refine the mesh such that the eigenfrequency which error committed the strongest violation of the global error requirement now falls within the tolerance, we may have that some of the other eigenfrequencies that committed a less strong violation also falls within the tolerance. In a such case we would not have to refine the mesh for those eigenfrequencies.

\section{Numerical example}

We shall now present some numerical tests designed to illustrate the $h$-version refinement strategy proposed in previous section. We attempt to analyse the accuracy of approximations on optimal meshes for the different eigenfrequencies. The performance of the adaptive strategy has been studied for the case of the transverse vibrations of $L$ shaped thin membrane of uniform thickness. An example has been solved with consistent mass matrix. Geometry and boundary conditions of this membrane are shown in Fig. 1.
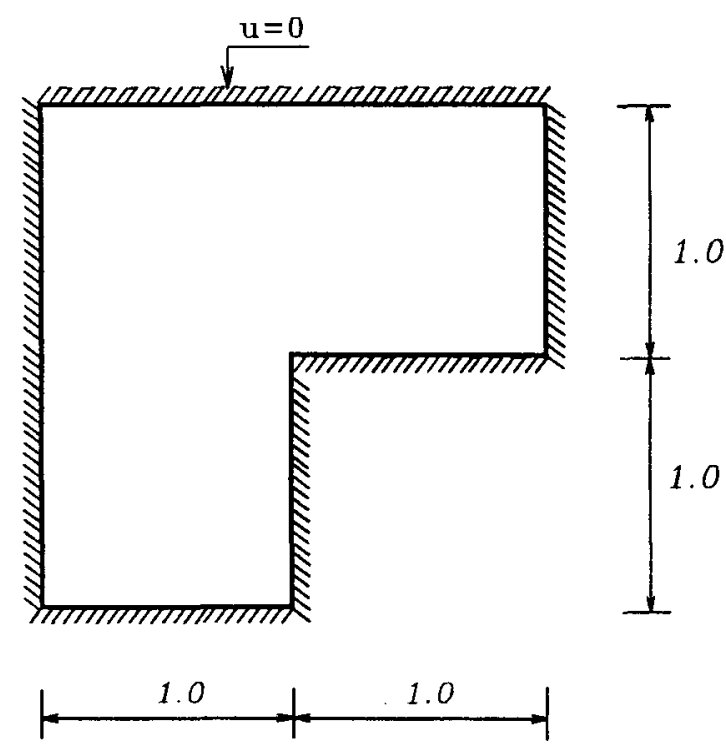

Fig. 1. Geometry and boundary conditions of the $L$-shaped membrane 
Wave propagation velocity $c=\sqrt{T / \rho}$ is assumed to be $1.0 \frac{\mathrm{m}}{\mathrm{s}}$, where $T$ is the uniform tension in the membrane. The permissible relative error in eigenfrequencies is $3.0 \%$ and relative error tolerance of finite element discretization is set to be $10.0 \%$. The triangular linear elements are used in this numerical experiment.

Accurate results for such a problem have been obtained by other authors [15], so that this may be regarded as a benchmark problem. These numerical results we accept as fully converged ones for the further validation of the proposed adaptive eigenfrequency analysis.

The initial finite element mesh for the adaptive analysis, shown in Fig. 2, is an uniform one and consists of 96 elements. The relative percentage errors in eigenfrequencies for this mesh are presented in Table 1 . The adaptive mesh refinement is performed using the errors of the finite element discretization in eigenmodes for the cases of 5-th, 7-th and 9-th eigenfrequencies.

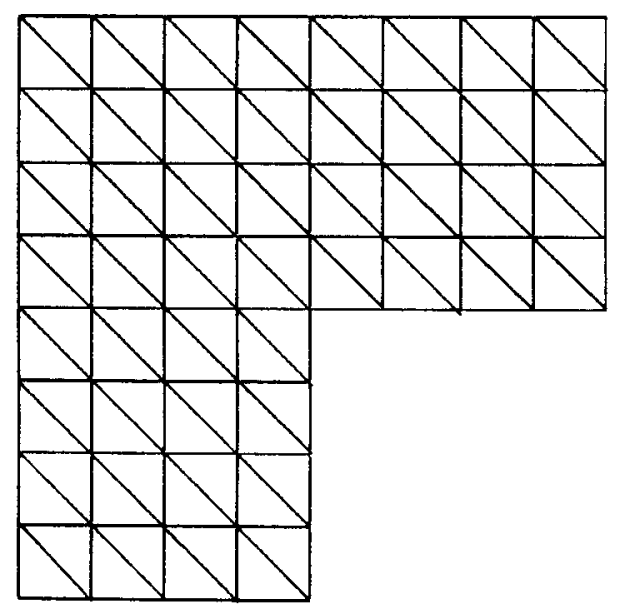

Fig. 2. Initial mesh for adaptive analysis of $L$-shaped membrane

Figures 3-5 show the adaptive mesh refinements for these eigenfrequencies. The relative percentage errors in eigenfrequencies for the optimal meshes of 5-th, 7-th and 9-th eigenfrequencies are shown in Tables 2-4. The adaptive analysis is completed by the single iteration for each eigenfrequency. For all presented cases, the studied range of eigenfrequencies meets the tolerance pre-specified as $3 \%$, but we have
Table 1. Relative errors in eigenfrequencies for initial mesh

\begin{tabular}{|c|c|c|}
\hline Mode & $\begin{array}{c}\text { Estimated relative } \\
\text { error in } \\
\text { eigenfrequencies (\%) }\end{array}$ & $\begin{array}{c}\text { True relative error in } \\
\text { eigenfrequencies (\%) } \\
{[15]}\end{array}$ \\
\hline 1 & 5.28 & 5.72 \\
\hline 2 & 4.51 & 4.58 \\
\hline 3 & 7.42 & 7.52 \\
\hline 4 & 9.06 & 9.25 \\
\hline 5 & 13.84 & 14.52 \\
\hline 6 & 12.87 & 13.47 \\
\hline 7 & 11.20 & 11.45 \\
\hline 8 & 14.51 & 14.82 \\
\hline 9 & 16.35 & 17.04 \\
\hline
\end{tabular}

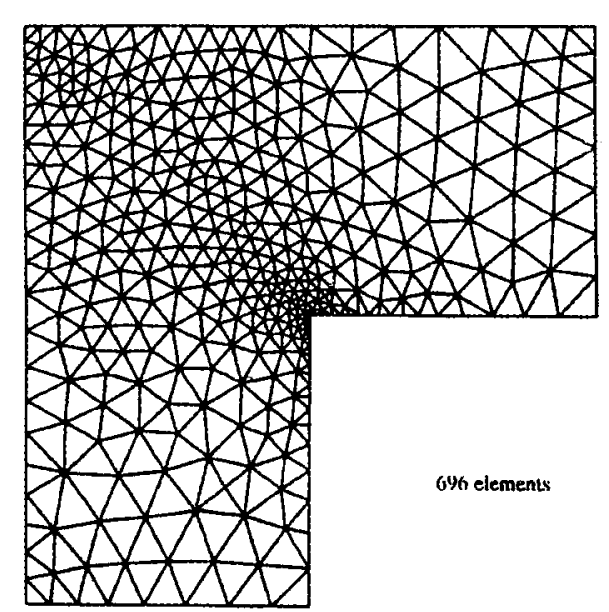

Fig. 3. Mesh obtained in adaptive analysis for the 5-th eigenfrequency of $L$-shaped membrane

Table 2. Relative errors in eigenfrequencies for optimal mesh of 5-th eigenfrequency

\begin{tabular}{|c|c|c|}
\hline Mode & $\begin{array}{c}\text { Estimated relative } \\
\text { error in } \\
\text { eigenfrequencies (\%) }\end{array}$ & $\begin{array}{c}\text { True relative error in } \\
\text { eigenfrequencies (\%) } \\
{[15]}\end{array}$ \\
\hline 1 & 0.609 & 0.596 \\
\hline 2 & 0.864 & 0.856 \\
\hline 3 & 1.074 & 1.069 \\
\hline 4 & 1.642 & 1.634 \\
\hline 5 & 1.365 & 1.354 \\
\hline 6 & 2.289 & 2.282 \\
\hline 7 & 2.434 & 2.445 \\
\hline 8 & 2.500 & 2.525 \\
\hline 9 & 2.970 & 2.948 \\
\hline
\end{tabular}




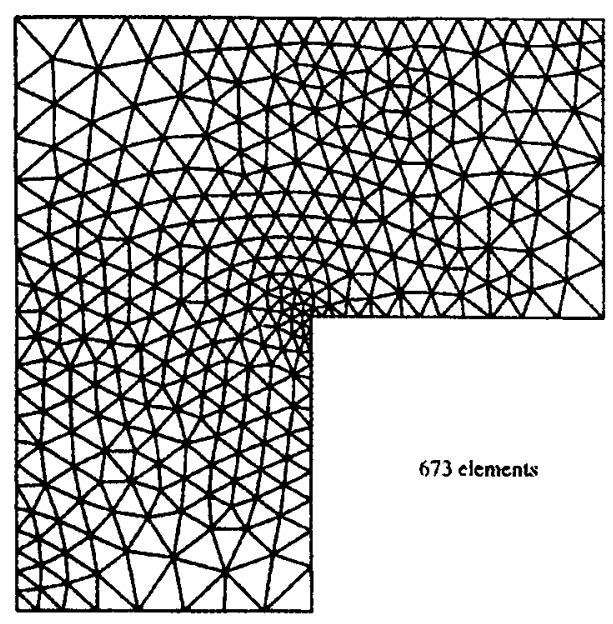

Fig. 4. Mesh obtained in adaptive analysis for the 7-th eigenfrequency of $L$-shaped membrane

Table 3. Relative errors in eigenfrequencies for optimal mesh of 7-th eigenfrequency

\begin{tabular}{|c|c|c|}
\hline Mode & $\begin{array}{c}\text { Estimated relative } \\
\text { error in } \\
\text { eigenfrequencies }(\%)\end{array}$ & $\begin{array}{c}\text { True relative error in } \\
\text { eigenfrequencies } \\
(\%)[15]\end{array}$ \\
\hline 1 & 0.609 & 0.606 \\
\hline 2 & 0.634 & 0.631 \\
\hline 3 & 0.900 & 0.896 \\
\hline 4 & 1.288 & 1.285 \\
\hline 5 & 1.579 & 1.563 \\
\hline 6 & 1.689 & 1.683 \\
\hline 7 & 1.696 & 1.687 \\
\hline 8 & 2.100 & 2.084 \\
\hline 9 & 2.367 & 2.362 \\
\hline
\end{tabular}

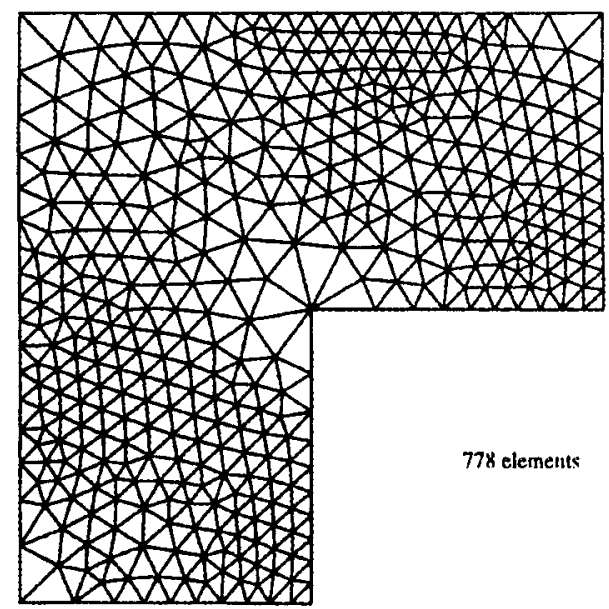

Fig. 5. Mesh obtained in adaptive analysis for the 9-th eigenfrequency of $L$-shaped membrane completely different meshes for each studied eigenfrequency. We can also observe that adaptive mesh based on the errors of the highest studied eigenfrequency provides the relative errors of all lower eigenfrequencies within pre-specified tolerance.

Table 4. Relative errors in eigenfrequencies for optimal mesh of 9-th eigenfrequency

\begin{tabular}{|c|c|c|}
\hline Mode & $\begin{array}{c}\text { Estimated relative } \\
\text { error in } \\
\text { eigenfrequencies (\%) }\end{array}$ & $\begin{array}{c}\text { True relative error in } \\
\text { eigenfrequencies } \\
(\%)[15]\end{array}$ \\
\hline 1 & 1.330 & 1.369 \\
\hline 2 & 0.722 & 0.549 \\
\hline 3 & 0.826 & 0.822 \\
\hline 4 & 1.071 & 1.047 \\
\hline 5 & 2.238 & 2.280 \\
\hline 6 & 1.939 & 1.958 \\
\hline 7 & 1.873 & 1.547 \\
\hline 8 & 1.519 & 2.505 \\
\hline 9 & 2.163 & 2.113 \\
\hline
\end{tabular}

\section{Conclusions}

The $h$-adaptive finite element strategy for free vibration problems is presented. For the error estimation global/local updating technique is employed. Adaptive process may be efficient only if the number of generated new meshes is minimal. Numerical experiments show that the proposed adaptive mesh refinement strategy can be completed by the single iteration for each eigenfrequency.

\section{References}

1. R.J.Melosh and P.V.Marcal. An energy basis for mesh refinement of structural continua // Internat. J. Numer. Methods Engrg., 11, 1977, p. 1083-1091.

2. I.Babuška and W.C.Rheinbolt. Reliable error estimation and mesh adoption for the finite element method // J.T.Oden ed., Computational Methods in Nonlinear Mechanics, Amsterdam, 1980, p.67-108.

3. J.Z.Zhu and O.C.Zienkiewicz. Adaptive techniques in the finite element method // Commun. Numer. Methods Engrg., 4, 1988, p.197-204.

4. B.A.Szabo. The $\mathrm{p}-$ and $\mathrm{h}-\mathrm{p}$ versions of the finite element method in solid mechanics // Comput. Methods Appl. Mech. Engrg., 80, 1990, p. 185-195.

5. W. Rachowicz, J.T.Oden and L.Demkowicz. Towards a universal h-p adaptive finite element strategy: Part III, Design of h-p meshes // Comput. Methods Appl. Mech. Engrg., 77, 1990, p. 181-212. 
6. L.Y.Li, P.Bettsess, J.W.Bull, T.Bond and I.Applegarth. Theoretical formulations for adaptive finite element computations // Commun. Numer. Methods Engrg., 11, 1995, p.857-868.

7. E.Onate and G.Budega. A study of mesh optimality criteria in adaptive finite element analysis // Engrg. Comput., 10, 1993, p. 307-321.

8. T.J.R.Hughes. The finite element method: Linear static and dynamic finite element analysis // Prentice- Hall, Englewood Cliffs, NJ, 1987. 789 p.

9. R.Baušys. Accuracy Estimates in Free Vibration Analysis // Building construction. Vilnius: Technika, 1995, No 4(4), p. 5-19.

10. N.-E.Wiberg and R.Baušys. Error estimation for eigenfrequencies and eigenmodes in dynamics // Eds. J.Pal and H.Werner, Computing in Civil and Building Engineering, A.A.Balkema, Rotterdam, 1995, p. 611616.

11. G.Gambolati, F.Sartoretto anf P.Florian. An orthogonal accelerated deflation technique for large symmetric eigenproblems // Comput. Methods Appl. Mech. Eng., 94, 1992, p. 13-23.

12. N.-E.Wiberg, R.Baušys and P.Hager. Adaptive hversion eigenfrequency analysis. // Chalmers University of Technology, Department of Structural Mechanics, Publ. 96:11, 1996. 40 p.

13. P.Hager, R.Baušys and N.-E.Wiberg. Improved eigenfrequencies and eigenmodes in dynamics // Ed. L.Damkilde, Ninth Nordic Seminar on Computational Mechanics, Lyngby, Denmark, October 1996, p. 245248.

14. O.C.Zienkiewicz, J.Z.Zhu and N.G.Gong. Effective and practical $h_{-p}$ version adaptive analysis procedures for the finite element method. // Internat. J. Numer. Methods Engrg., 28, 1989, p. 879-891.

15. R.Hettich and G.Still. Local aspects of a method for solving membrane-eigenvalue problems by parametric semi-infinite programming $/ /$ in Eds. J.Guddat, H.T.Jongen, B.Kummer and F.Nozicka, Parametric Optimization and Related Topics. Berlin: AkademieVerlag, 1987, p.183-195.

Iteikta 19961210

\section{PRISTTAIKANČIOJI BAIGTINIU ELEMENTU STRATEGIJA LAISVŲJU SVYRAVIMU UŽDAVINIAMS SPRĘSTI}

\section{R. Baušys}

\section{S a n tra u k a}

Norint rasti pageidaujamo 'tikslumo inžineriniy̨ uždavinių sprendimus, naudojamos jvairios prisitaikančiosios baigtiniy elementy strategijos. Straipsnyje pateikta prisitaikančiosios baigtinių elementų strategijos h-versija, skirta laisvyjų svyravimy uždaviniams spręsti. Jos esmę sudaro naujo diskretizacijos tinklo generavimas, naudojant tos pačios eilès baigtinius elementus. Šios strategijos tikslas - sugeneruoti optimaly baigtiniy elementy tinkla, kuris apibūdinamas tolygiu diskretizacijos paklaidu pasiskirstymu. Diskretizacijos paklaidos randamos poprocesoriniais lokaliniu ir globaliniu būdais. Atlikti skaitiniai eksperimentai atskleidè pasiūlytos prisitaikančiosios baigtiniy elementy strategijos efektyvuma, nes optimalus diskretizacijos tinklas buvo suformuotas kiekvienai tyrinetai nuosavai reikšmei, panaudojant tiktai vieną algoritmo iteraciją.

Romualdas BAUŠYS. Doctor, Associate Professor. Department of Engineering Mechanics. Vilnius Gediminas Technical University (VGTU), 11 Sauletekio Ave, 2040 Vilnius, Lithuania.

R.Baušys started working at Vilnius Technical University in 1982. Doctoral thesis in 1989 Common research with scientists from Chalmers University of Technology (Göteborg, Sweden). Studies into optimization and analysis procedures for non-linear problems. Research interests: problems of error estimation and adaptive finite element strategies in statics and dynamics. 